\title{
O USO DE SIMULAÇÕES COMPUTACIONAIS PARA COMPREENSÃO DO CONCEITO DE ÁCIDO E BASE
}

\author{
NILMA SOARES DA SILVA \\ Mniversidade Federal de Minas Gerais. Faculdade de Educação. Doutora. \\ ORCID: https://orcid.org/0000-0003-4692-122X. E-mail: nilmafaeufmg@gmail.com

\section{FERNANDO CÉSAR SILVA} \\ Universidade Federal de Minas Gerais. Faculdade de Educação. Doutor. \\ ORCID: https://orcid.org/0000-0002-2059-4550. E-mail: fscquimico@yahoo.com.br

\section{EDYTH PRISCILLA CAMPOS SILVA} \\ Professora da Educação Básica. ORCID: https://orcid.org/0000-0002-6678-8537. \\ E-mail: edythpriscilla@gmail.com
}




\section{USO DE SIMULAÇÕES COMPUTACIONAIS PARA COMPREENSÃO DO CONCEITO DE ÁCIDO E BASE}

Muitos estudantes não compreendem os conceitos de ácido e base, utilizando apenas definições e desconsiderando a influência do solvente nas propriedades dessas substâncias. As simulações computacionais permeadas por uma abordagem investigativa podem ser promissoras para minimizar essas dificuldades dos estudantes, pois favorece ambientes em que fenômenos podem ser observados e estudados no nível submicroscópico e de forma dinâmica. Neste artigo foi proposto o uso da simulação computacional disponível no site PhET com uma abordagem investigativa para discussão de conceitos de ácido e base. Para compreensão das atividades propostas durante a simulação foi utilizada a Análise Textual Discursiva. Os estudantes levantaram hipóteses, testaram essas hipóteses com o uso direcionado da simulação por meio de um roteiro com um maior nível de abertura, observaram a influência do solvente nas propriedades ácidas e básicas das substâncias e representaram o comportamento dessas substâncias em água usando modelos. Ao explorarem a simulação os estudantes puderam compreender de uma forma mais integrada os conceitos de ácido e base, mostrando assim o potencial da simulação para discussão desses conceitos nas aulas de Química.

Palavras chaves: Educação Química. Ensino de Ciências por Investigação. Tecnologias de Informação e Comunicação. Ensino Médio.

\section{THE USE OF COMPUTATIONAL SIMULATIONS FOR UNDERSTANDING THE CONCEPT OF ACID AND BASE}

Many students do not understand the concepts of acid and base, using only definitions and disregarding the influence of the solvent on the properties of these substances. Computational simulations permeated by inquiry learning can be promising to minimize these students difficulties because it favors environments which phenomena can be observed and studied at the submicroscopic level and dynamically.In this paper, we suggest the use of the computational simulation available in the PhET site with an inquiry learning to discussing acid and base concepts. To understand the activities proposed during the simulation, the Discursive Textual Analysis was used. The Students raised hypothesis, tested this hypothesis with directed use of the simulation through a script with the highest level of aperture, they observed the influence of the solvent on the acidic and basic properties of the substances and represented the behavior of these substances in water using models. By exploring the simulation the students were able to understand in a more integrated way the concepts of acid and base, thereforeshowing the potential of the simulation to discuss these concepts in Chemistry classes.

Keywords: Chemistry Education. Inquiry-based in Science Education. Information and Communication Technology. High School. 


\section{EL USO DE SIMULACIONES COMPUTACIONALES PARA ENTENDER EL CONCEPTO DE ACIDO Y BASE}

Muchos estudiantes no entienden los conceptos de ácido y base, utilizando sólo definiciones y desconsiderando la influencia del solvente en las propiedades de esas sustancias. Las simulaciones computacionales permeadas por un enfoque investigativo pueden ser prometedoras para minimizar esas dificultades de los estudiantes, pues favorece ambientes en que fenómenos pueden ser observados y estudiados en el nivel submicroscópico y de forma dinámica. En este artículo se propuso el uso de la simulación computacional disponible en el sitio PhET con un enfoque investigativo para discusión de conceptos de ácido y base. Para la comprensión de las actividades propuestas durante la simulación se utilizó el análisis textual discursivo. Los estudiantes levantaron hipótesis, probaron esas hipótesis con el uso direccionado de la simulación por medio de un itinerario con un mayor nivel de apertura, observaron la influencia del solvente en las propiedades ácidas y básicas de las sustancias y representaron el comportamiento de esas sustancias en agua usando modelos. Al explorar la simulación los estudiantes pudieron comprender de una forma más integrada los conceptos de ácido y base, mostrando así el potencial de la simulación para discusión de esos conceptos en las clases de Química.

Palabras-clave: Educación Quimica. Enseñanza de Ciencias por Investigación. Tecnologías de Información y Comunicación. Esculea Secundaria. 


\section{O USO DE SIMULAÇÕES COMPUTACIONAIS PARA COMPREENSÃO DO CONCEITO DE ÁCIDO E BASE}

\section{Introdução}

A análise das concepções alternativas de estudantes do Ensino Médio, a respeito de ácidos e bases, indica que muitos deles têm dificuldades ou apresentam uma visão contínua da matéria (OLIVEIRA, 2008). Quando os estudantes utilizam definições para conceituar ácidos e bases, geralmente mencionam a definição de Arrhenius de forma limitada, como por exemplo "[...] pensam no conceito de ácido como se fossem palavras: conter hidrogênio" (OLIVEIRA, 2008, p. 42). Eles apresentam dificuldades em relacionar a definição de ácido e base de Arrhenius com partículas, e a dissociação e ionização dessas. Consequentemente, discutir sobre a força de substâncias ácidas e básicas é ainda mais complicado, pois este conceito está intimamente ligado a, respectivamente, ionização e dissociação dessas substâncias. Essas dificuldades sugerem que os estudantes apenas memorizam as definições, não conseguindo aplicá-las nos diferentes contextos de forma adequada.

Considerando a dificuldade de se compreender esses conceitos e a necessidade de se pensar abordagens que possam contribuir para uma compreensão que leva em consideração as dificuldades discutidas anteriormente; torna-se necessária a busca de recursos que minimizem essas dificuldades e favoreçam a aprendizagem. A compreensão dos conceitos químicos perpassa por três aspectos principais, conforme indicado no Conteúdo Básico Comum de Minas Gerias:

\footnotetext{
É didaticamente interessante distinguir as três formas de abordagem para os conceitos químicos: os fenômenos; as teorias e modelos explicativos; e as representações. Envolvendo tais aspectos conceituais, as diferentes formas de abordagem possibilitam ao estudante o desenvolvimento de habilidades e atitudes de investigação e compreensão acerca dos fenômenos associados à Química. Tais aquisições baseiam-se na convivência com a linguagem simbólica/representacional dessa ciência e na apropriação de conceitos e sistemas teóricos que capacitam o estudante a dar explicações lógicas dentro desse campo de estudo e dos fenômenos que o cercam em sua vida em sociedade (MINAS GERAIS, 2008, p. 16).
}

Sendo assim, as simulações computacionais podem ser interessantes para facilitar o entendimento de todas essas formas de abordagem para os conceitos químicos, principalmente, 
as teorias e modelos explicativos, e as representações. Ribeiro e Greca (2003) discorrem que dentre as diferentes estratégias didáticas, esse tipo de recurso tem tido destaque, pois propicia ao estudante "explorar fenômenos, processos e ideias abstratas" (p. 544). Tradicionalmente, os meios usados pelos professores para auxiliar na compreensão do nível submicroscópico "consistiam em representações pictóricas, esquemáticas ou modelos estáticos" (RIBEIRO; GRECA, 2003, p. 544). Hoje, porém, esses profissionais podem usufruir de modelos que representem essa ciência de forma dinâmica. Nesse sentido, as simulações, ou seja, os "programas que contêm um modelo de um sistema ou processo" (DE JONG; VAN JOOLINGEN, 1998 citado por RIBEIRO; GRECA, 2003, p. 544), se tornam grandes aliados ao processo de ensino e aprendizagem, se forem adaptados à uma abordagem investigativa (RIBEIRO; GRECA, 2003). Logo, para que esse recurso seja efetivo, utilizar-se-á a abordagem investigativa, cujo objetivo é criar um ambiente em que os professores possam ensinar, de modo simplificado, o processo do trabalho científico, reconhecendo que os objetivos da investigação na ciência são diferentes do ensino. A abordagem investigativa além de aproximar os estudantes da cultura científica coloca-os no papel de protagonista da construção do seu próprio conhecimento. Sobre isto, Driver e colaboradores (1999, p. 36) argumentam que,

Aprender ciências envolve a introdução das crianças e adolescentes a uma forma diferente de pensar sobre o mundo natural e de explicá-lo; é tornar-se socializado, em maior ou menor grau, nas práticas da comunidade científica, com seus objetivos específicos, suas maneiras de ver o mundo e suas formas de dar suporte às assertivas do conhecimento. Antes que isso possa acontecer, no entanto, os indivíduos precisam engajar-se em um processo pessoal de construção e de atribuição de significados.

\section{Referencial Teórico}

\section{Simulações Computacionais}

Paula (2015) aponta que alguns critérios distinguem animações, simulações e os laboratórios virtuais. O critério interatividade caracteriza as simulações e pode oscilar entre baixo, médio e alto. Quanto maior o número de variáveis e da interação entre elas, maior será o grau de interatividade presente. O tipo de informação produzida é outro critério, o que no caso das simulações podem ser quantitativas, mas não exclusivamente. $O$ tipo de representação encontrada e de objetos que essas representações substituem é outro critério e nas simulações predominam as representações de entidades e processos que constituem os modelos científicos. "No caso das simulações, a interação do estudante se dá com entidades e processos cuja existência depende da 
adesão a uma teoria, como é o caso da energia dos fótons que incidem sobre um modelo do átomo e Bohr". (PAULA, 2015, p.187)

Desde 1989 avanços têm acontecido e hoje as tecnologias da informação e comunicação (TIC) fazem parte do dia a dia. Consequentemente, não passaria também despercebida da área de Educação, em especial da Educação Química, pois permite a criação de ambientes de aprendizagem que ultrapassam as possibilidades que outros recursos dariam, como por exemplo, o livro didático. Como discutido, os estudantes possuem uma visão contínua da matéria, logo a simulação pode ser um recurso útil para a construção da compreensão das teorias e modelos utilizados em Química.

A tecnologia em ambientes educacionais proporciona aulas mais interessantes, originam oportunidades de "feedback, reflexão e revisão, [...] possibilita aos estudantes a compreensão da relação causal entre as variáveis, com o isolamento e a manipulação de um parâmetro por vez e o teste de hipóteses alternativas". Contudo, Ribeiro e Greca (2003, p. 545) ressaltam que:

É de certa forma paradoxal verificar que, diante de tanto desenvolvimento de tecnologia educacional voltada para Química, a quantidade de relatos sobre implementação efetiva destas ferramentas seja em número tão reduzido, sendo igualmente escassa a quantidade de artigos voltados à pesquisa sobre o uso desta tecnologia, com vistas a proporcionar embasamento teórico e técnico para que os professores, sentindo-se seguros, trabalhem em sua prática pedagógica.

Porém, o uso da simulação não garante uma compreensão adequada do mundo submicroscópico. Brasileiro e Silva (2015) afirmam que como as simulações são baseadas em modelos criados para os fenômenos naturais elas são limitadas. As autoras também discorrem que os objetivos do uso da simulação devem estar bem claros para o professor e para os estudantes, e para isso pode-se propor um roteiro que oriente a interação dos estudantes com a simulação visando atingir esses objetivos. Sobre isso as autoras afirmam:

Entendemos que disponibilizar essa ferramenta aos alunos sem orientar o seu uso é correr o risco de usar a tecnologia como diversão, quando, na realidade, ela pode ser extremamente útil para o processo de aprendizagem.

(BRASILEIRO; SILVA, 2015, p. 42) 
$\mathrm{Na}$ simulação computacional é possível fazer uso de apenas algumas ferramentas disponíveis, o professor deve selecioná-las e direcionar os estudantes de acordo com seu objetivo (BRASILEIRO; SILVA, 2015). Giordan (1999, p. 47) argumenta que,

Nas situações de simulação, desencadeia-se um jogo entre os elementos e as relações, que devem manter correspondência com seus análogos no plano do fenômeno. É nesse palco de simulações que podem se formar ambientes estimuladores para a criação de modelos mentais pelo sujeito, que passa a reconhecer nos modelos ora simulados a primeira instância de representação analógica da realidade.

Logo, o presente trabalho pode contribuir para incentivar e ajudar professores no uso dessa ferramenta, pois, como já discutido, ela pode oferecer ferramentas úteis para facilitar a compreensão dos estudantes de assuntos mais abstratos.

\section{Atividades Investigativas}

As atividades investigativas proporcionam ambientes em que os estudantes aprendam de forma individual e social (CARVALHO, 2013), pois almeja-se que os estudantes sejam "capazes de construir significados essenciais com suas próprias palavras" (LEMKE, 1997). As atividades baseadas na investigação abrangem um tópico do conteúdo previsto no programa escolar, e cada uma das atividades é planejada de forma a fazer com que os estudantes tragam para a sala seus conhecimentos prévios, e a partir deles, construam os novos. Eles propõem ideias para solucionar problemas que serão discutidos com o professor e colegas. O problema deve ser do contexto social do estudante, como também ser instigante o bastante para que eles sintam vontade de resolvê-lo. Em seguida, o professor disponibiliza ferramentas para que os estudantes testem suas hipóteses e resolvam o problema proposto. É aconselhável que esta etapa seja feita em grupo para que, como dito anteriormente, o estudante discuta, interaja, argumente etc (CARVALHO, 2013).

Para finalizar, depois dos estudantes terminarem a atividade, o professor discute como eles chegaram à conclusão final, como isso aconteceu etc. É neste momento de explicação por parte dos estudantes, que eles procuram por um conceito que explique o fenômeno estudado, e é também nesta etapa que os estudantes podem ampliar seu vocabulário científico. Em seguida, o estudante, sistematiza individualmente o que aprendeu. Isso pode ser feito por um desenho, uma produção textual, gráficos etc (CARVALHO, 2013). 
Diante do exposto, analisamos como uma simulação computacional aliada à abordagem investigativa auxiliou os estudantes na compreensão do nível submicroscópico dos conceitos de ácido e base e sua força segundo a teoria de Arrhenius.

\section{Metodologia}

A simulação usada foi "Soluções Ácido Base" do programa PhET (disponível em https:// phet.colorado.edu/pt_BR/simulation/acid-base-solutions) e faz parte de uma sequência didática elaborada com o objetivo de trabalhar a definição de Arrhenius para ácidos e bases e o conceito de força dessas substâncias. Para isso foi utilizada a abordagem investigativa (CARVALHO, 2013) utilizando como recurso uma simulação computacional. Esta sequencia foi trabalhada com 34 estudantes do segundo ano do Ensino Médio de uma escola da Rede Estadual de ensino da cidade de Belo Horizonte. A sequência didática foi dividida em três etapas, cada uma tendo uma ou duas aulas de 50 minutos, totalizando 4 horas aula e cinco atividades, sendo elas: levantamento de concepções prévias; leitura do texto problematizador; elaboração de hipóteses; exploração da simulação e atividade de sistematização.

Na simulação os conceitos de ácido e base são trabalhados segundo a definição de Arrhenius, incluindo: i) concentração e pH das soluções ácidas e básicas; ii) diferença entre ácidos e bases fortes e fracas; iii) diferença das propriedades ácidas e básicas em diferentes solventes e, iii) uso virtual de instrumentos de laboratório (medidor de $\mathrm{pH}$, condutividade, papel de $\mathrm{pH}$ ).

A simulação apresenta duas abas. A primeira, "Introdução", como visto na figura 1, inclui quatro soluções, ácido forte, ácido fraco, base forte, base fraca e água pura. É possível ver a representação das partículas, medir o $\mathrm{pH}$ e verificar a condutividade elétrica. Na segunda aba intitulada "Minha Solução", o estudante pode mudar a concentração inicial da solução e a força do ácido ou da base. Ele também pode medir o $\mathrm{pH}$ em todas as situações escolhidas. Em ambas as abas mostram-se as equações de dissolução e ionização das substâncias e gráficos de concentração. 
Figura 1. Aba "Introdução" simulação "Soluções Ácido-Base"

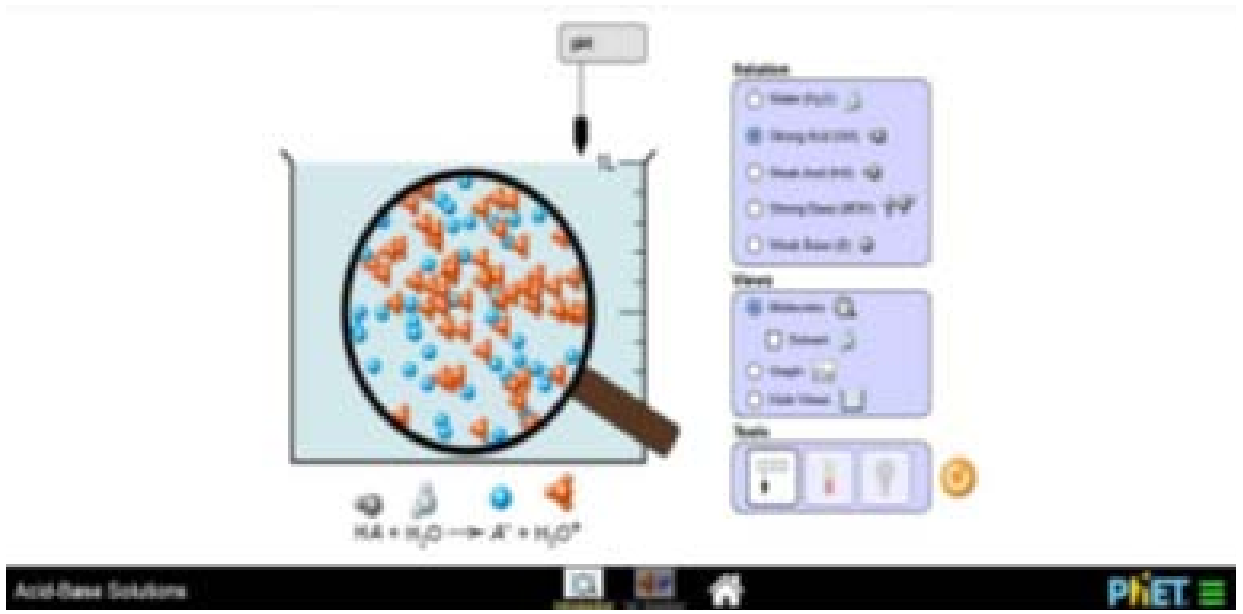

Fonte: BBanco de Imagens da ESVC

Para a exploração da simulação foi disponibilizado aos estudantes um roteiro para orientálos. Foram escolhidas apenas algumas ferramentas disponíveis da simulação, pois o objetivo era fazer com que os estudantes observassem o comportamento dos ácidos fortes e fracos e das bases fortes e fracas em água e também concluíssem que ao mudar a concentração, os ácidos ou a bases, não mudavam sua propriedade de ser forte ou fraco. O roteiro é essencial pois, como apontado por Driver e colaboradores (1999), o conhecimento é apreendido quando um membro mais experiente de uma cultura (no caso aqui a escolar) ajuda os membros menos experientes estruturando as tarefas, ajudando-os a executá-las e internalizá-las. Isso fica mais claro a partir da citação usando os esses autores:

As entidades e ideias científicas, que são construídas, validadas e comunicadas através das instituições culturais da ciência, dificilmente serão descobertas pelos indivíduos por meio de sua própria investigação empírica; aprender ciências, portanto, envolve ser iniciado nas ideias e práticas da comunidade científica e tornar essas ideias e práticas significativas no nível individual. $\mathrm{O}$ papel do professor de ciências, mais do que organizar o processo pelo qual os indivíduos 
geram significados sobre o mundo natural, é o de atuar como mediador entre o conhecimento científico e os aprendizes, ajudando-os a conferir sentido pessoal à maneira como as asserções do conhecimento são geradas e validadas. Portanto, essa perspectiva pedagógica difere fundamentalmente da perspectiva empirista. (DRIVER et al, 1999, p. 32 e 33)

Antes dos estudantes explorarem a simulação foi lido e discutido um um texto para proposição de um problema, "BreakingBad II - Eliminação de corpos no banho de ácido", escrita por Jonathan Hare para a coluna "Química na tela" do site "Education in Chemistry” " ,. Dessa forma, foi proposto o seguinte problema: "O ácido fluorídrico (HF) é um ácido considerado fraco, apesar da sua capacidade de corrosão. Se Jesse usasse uma solução de ácido fluorídrico mais concentrada, aumentaria sua força?".

O problema é de fácil interpretação e muito intrigante, pois questiona os estudantes sobre um personagem de uma série mundialmente conhecida. Além disso, ácidos e bases são trabalhados desde o $1^{\circ}$ ano do Ensino Médio, e são também constantemente utilizados no cotidiano, o que favorece aos estudantes a utilização de seus conhecimentos anteriores para elaborar suas hipóteses.

A aula seguinte iniciou-se retomando o texto e a atividade de levantamento de hipóteses. Em duplas, os estudantes foram instruídos a reler suas hipóteses e a explorar a simulação de forma a testar suas hipóteses. O roteiro apresentou uma sequência de comandos que, aos poucos, exigia observações mais complexas. Primeiramente foi trabalhado o comportamento de ácido e de bases fortes e fracas em solução. Os estudantes deveriam relacionar o número de espécies de acordo com a equação química, primeiramente fazendo um levantamento empírico, depois analisando os dados do gráfico. Os comandos que se seguiam objetivavam que os estudantes observassem que a proporção das espécies não mudavam ao variar a concentração. Eles deveriam mover a barra de concentração e observar o número de espécies no recipiente e também analisar o gráfico de acordo com a equação química mostrada. Ou seja deveriam observar que o número de espécies variava proporcionalmente ao mudar a concentração.

Para finalização da sequência de aulas, discutiu-se com os estudantes uma reportagem a fim de que eles produzissem um texto. Esta etapa foi a sistematização individual do estudante e também procurou avaliar como a sequência pôde contribuir para o entendimento sobre o tema abordado.

\footnotetext{
${ }^{1}$ Diponível em https://eic.rsc.org/analysis/breaking-bad-ii-acid-bath-disposal-ofbodies/3007374.article.
}

\section{P/U $a$ i $S$ Salvador, v. 4, n. 2, p. 47-64, mai./ago. 2019}


Na reportagem foi relatada a erupção do vulcão Kilauea no Hawaí que acarretou danos ambientais e ofereceu riscos à saúde da população local. Os estudantes tiveram que produzir um texto explicando cientificamente o trecho contido na reportagem: “[...] essa perigosa combinação pode formar nuvens que chegam a 1.093 graus Celsius e que reagem com a água do mar" ${ }^{2}$. Esperava-se que os estudantes usassem os conceitos trabalhados nas outras atividades agora em outro contexto, pois conforme Driver e colaboradores (1999) o desafio da educação é fazer com que os aprendizes se apropriem dos modelos científicos, reconheçam seus domínios de aplicabilidade e dentro desses domínios sejam capazes de usá-los. Esperava-se que os estudantes mencionassem na produção textual a ionização do ácido clorídrico quando esse entra em contato com a água. Nesta terceira etapa os estudantes usaram duas aulas de 50 minutos para concluir as atividades propostas.

Para análise dos dados produzidos foi utilizada a Análise Textual Discursiva. Esta análise consiste em um método qualitativo de análise de textos que visa construir respostas a questionamentos propostos RAMOS; RIBEIRO; GALIAZZI, 2015. "Pode ser compreendido como um processo auto-organizado de construção de novos significados em relação a determinados objetos de estudo" (MORAES; GALIAZZI, 2011, p. 45). O processo de análise se inicia com a codificação do material analisado. Isso facilita a localização dos fragmentos que foram utilizados para exemplificar a análise feita. Em seguida há a desconstrução dos textos a partir da "unitarização do corpus" (RAMOS; RIBEIRO; GALIAZZI, 2015). A unitarização do texto consiste na retirada de fragmentos, que Ramos, Ribeiro e Galiazzi (2015) denominam como unidades de sentido ou de análise.

O passo seguinte da análise é a categorização das unidades selecionadas. Essa categorização consiste em agrupar as unidades de sentido semelhantes. Se, as categorias não foram estabelecidas previamente, diz-se que elas emergem do texto (RAMOS; RIBEIRO; GALIAZZI, 2015). Ou seja, "elas são criadas e nomeadas com base no significado comum das unidades de sentido" (RAMOS; RIBEIRO; GALIAZZI, 2015, p. 128). Porém, se as categorias forem estabelecidas previamente, Ramos, Ribeiro e Galiazzi (2015) afirmam que o corpo teórico deve ser muito bem definido, ou seja, quem analisa com categorias previamente estabelecidas deve estar ciente do que pode encontrar nos registros escritos ou, por exemplo, construir as atividades com o objetivo de aparecer as categorias que deseja.

${ }^{2}$ Diponível em https://eic.rsc.org/analysis/breaking-bad-ii-acid-bath-disposal-ofbodies/3007374.article. 
As unidades de sentido podem ser reagrupadas em categorias que são próximas quantas vezes o analista achar necessário. Esse reagrupamento objetiva obter um grupo de categorias mais compactas e abrangentes. As categorias finais "consistem em um conjunto de enunciados que expressam respostas às questões de pesquisa" (RAMOS; RIBEIRO; GALIAZZI, 2015, p. 128). Depois das categorias finais estabelecidas, inicia-se o processo de construção dos metatextos. Eles são a interpretação e a explicação do pesquisador do corpus analisado. Ou seja, trata-se da sua reflexão sobre as marcas. Ramos, Ribeiro e Galiazzi (2015, p. 128), deixam isso claro quando discorrem:

\begin{abstract}
A produção dos metatextos é um exercício de autoria e de preparação de argumentos a serem comunicados com vistas à validação do que foi compreendido sobre o corpus analisado. De modo que a partilha dos pensamentos de cada sujeito com o grupo durante a escrita, a partir das categorias finais, torna consistente a ideia gerada pelo grupo, favorecendo aprendizagens individuais sobre o tema com superação e ampliação da compreensão de partida.
\end{abstract}

A construção desses metatextos leva em consideração a contribuição de referenciais teóricos pertinentes à análise. Eles ajudam e corroboram com a interpretação do pesquisador. Essa interpretação deve se atentar aos significados que o próprio texto já diz. Ela pretende "compreender o dito e não dito; o explícito e o não explícito ou o tácito" (RAMOS; RIBEIRO; GALIAZZI, 2015, p. 129), mas não dizer o que o texto não diz, e nem juízo de valor das ideias ali apresentadas pelos autores das produções textuais, ou seja, procura-se fazer uma interpretação dos textos a fim de identificar e compreender o que os sujeitos querem dizer (RAMOS; RIBEIRO; GALIAZZI, 2015).

\title{
Resultados e discussão
}

Foram analisados 11 registros sobre a elaboração de hipóteses (atividade em grupo), 18 registros do roteiro da simulação (atividade em grupo), 30 produções textuais (atividade individual). A elaboração de hipóteses juntamente com o roteiro da simulação foi codificada pela letra $\mathrm{R}$ seguida por seu número (essa numeração foi escolhida arbitrariamente). As produções textuais, por terem sido feitas individualmente, foram codificadas com a letra E seguida por um número que foi escolhido por ordem alfabética dos estudantes. Os excertos retirados dos registros dos estudantes foram transcritos de forma literal, quando há erros ortográficos a sentença ou palavra é sublinhada. 
As categorias elaboradas a seguir mostram a compreensão dos estudantes sobre ácidos e bases depois de aplicada a sequência didática. Essas categorias não foram previamente estabelecidas, pois o objetivo era conhecê-las e ter a mínima interferência do interpretante, deixando então, que emergissem das respostas.

\section{Concepção do comportamento de ácidos e bases em água}

A simulação computacional representava o modelo da ionização do ácido e dissociação da base em água relacionando cada espécie com a equação química como visto, por exemplo, para ácidos e bases fortes nas Figuras 2 e 3 . Os estudantes foram convidados a observar o número de cada espécie formada provenientes do ácido e da base forte e fraca. Para ácidos e bases fortes os estudantes observaram que essas espécies reagem melhor com água formando mais produtos.

Figura 2. Ionização de ácido forte em água

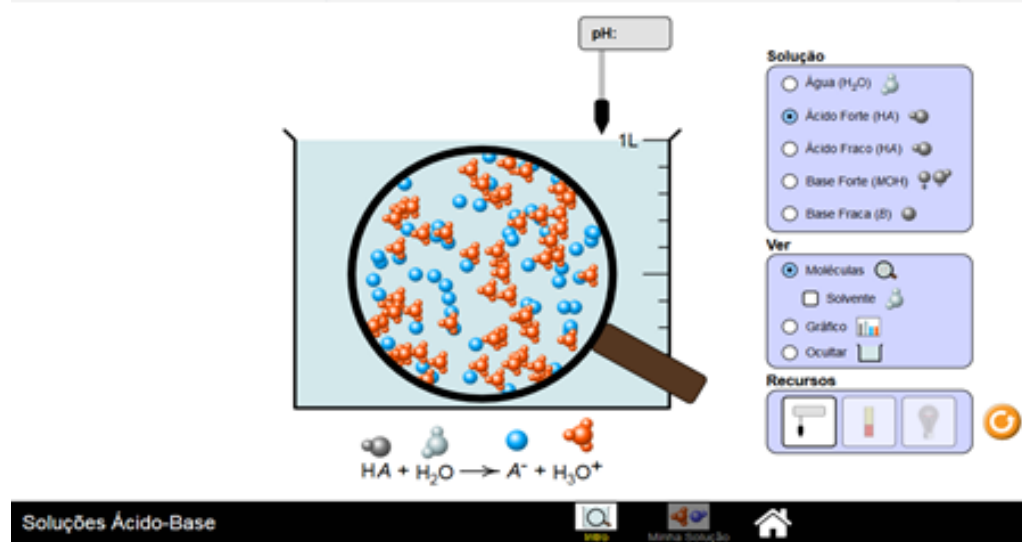

Fonte: Site PhET 
Figura 3. Dissociação de base forte em água

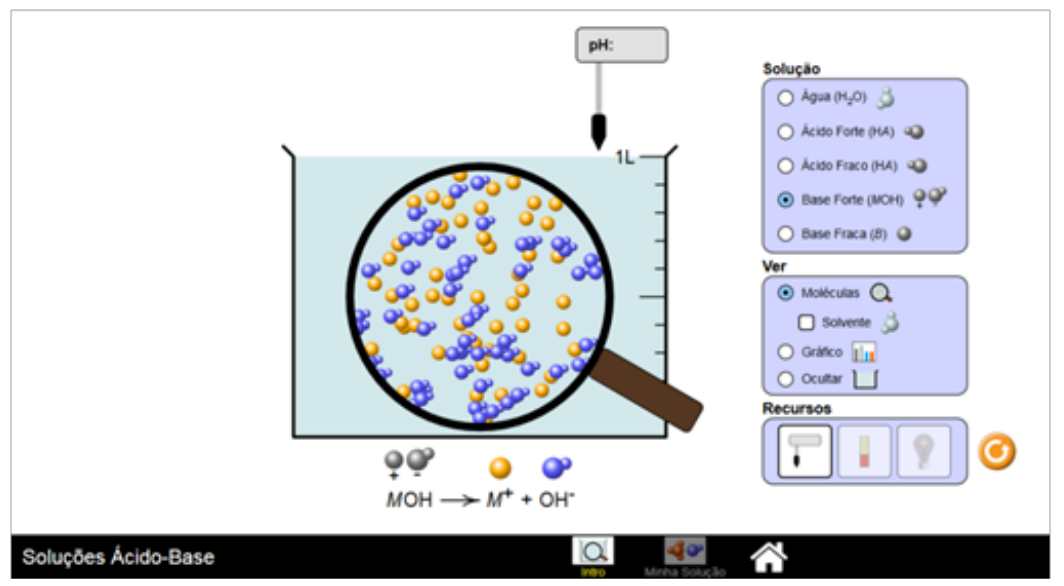

Fonte: Site PhET

Os excertos do relatório R12 ilustraram bem o que os estudantes observaram do fenômeno:

R12: "Já no ácido forte já é formado mais partículas de A- e H3O+ . Em base forte o MOH se quebra formando mais 46 partículas de $\mathrm{M}+\mathrm{e} \mathrm{OH}-. "$

Para ácidos e bases fracas os estudantes observaram que as substâncias reagem, porém, em menor proporção:

R06: "Na base fraca apresenta muita água e poucos íons, também apresenta pouca dissociação ao reagir com a água."

R00 "Na lupa é possível notar que há grande quantidade de $\mathrm{HA} \mathrm{e} \mathrm{H2O} \mathrm{e} \mathrm{poucas}$ de $\mathrm{A}-\mathrm{e} \mathrm{H} 3 \mathrm{O}+. "$

Como discutido, os estudantes têm dificuldade, ou não apresentam uma visão particulada da matéria, mas antes a descreve como um modelo contínuo (OLIVEIRA, 2008). Porém, ao trabalhar a simulação computacional em sala proporcionou-se um ambiente em que os estudantes visualizassem o modelo do comportamento das espécies fortes e fracas em água. E então, compreendessem os ácidos e bases como partículas e não apenas por definições memorizadas como "conter hidrogênio". 


\section{Concepção da força de ácidos e bases em água}

Nos roteiro para exploração da simulação foi pedido aos estudantes que observassem a variação da concentração das soluções com ácidos fortes como visto nas Figuras 4 e 5, e posteriormente com ácidos fracos.

Figura 4. Ionização de ácido com concentração de $0,002 \mathrm{~mol} / \mathrm{L}$

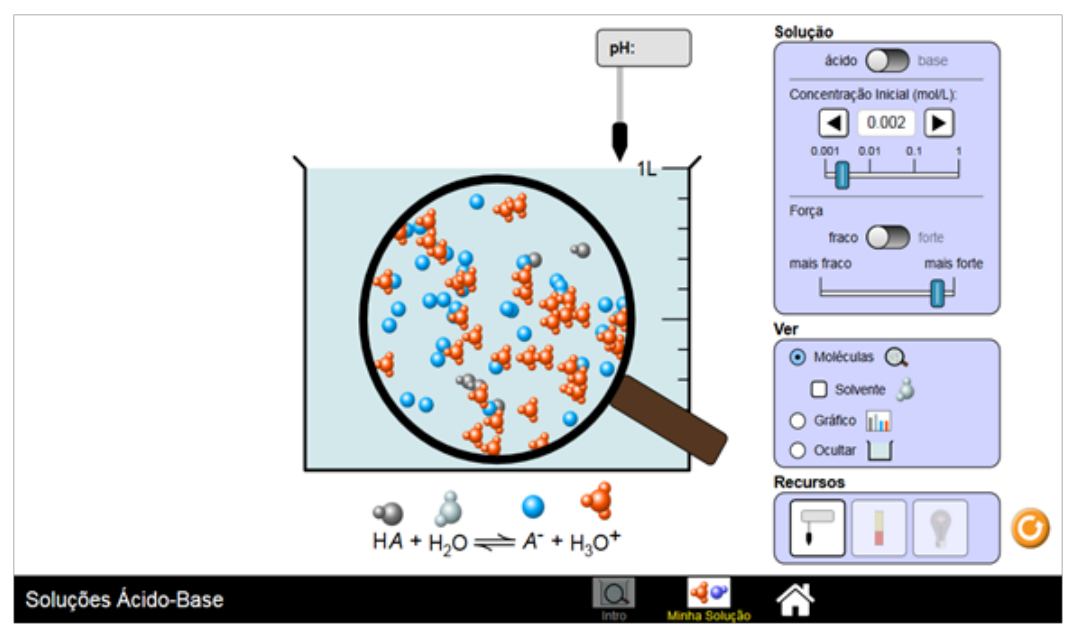

Fonte: Site PhET

Figura 5. Ionização de ácido com concentração de $0,200 \mathrm{~mol} / \mathrm{L}$

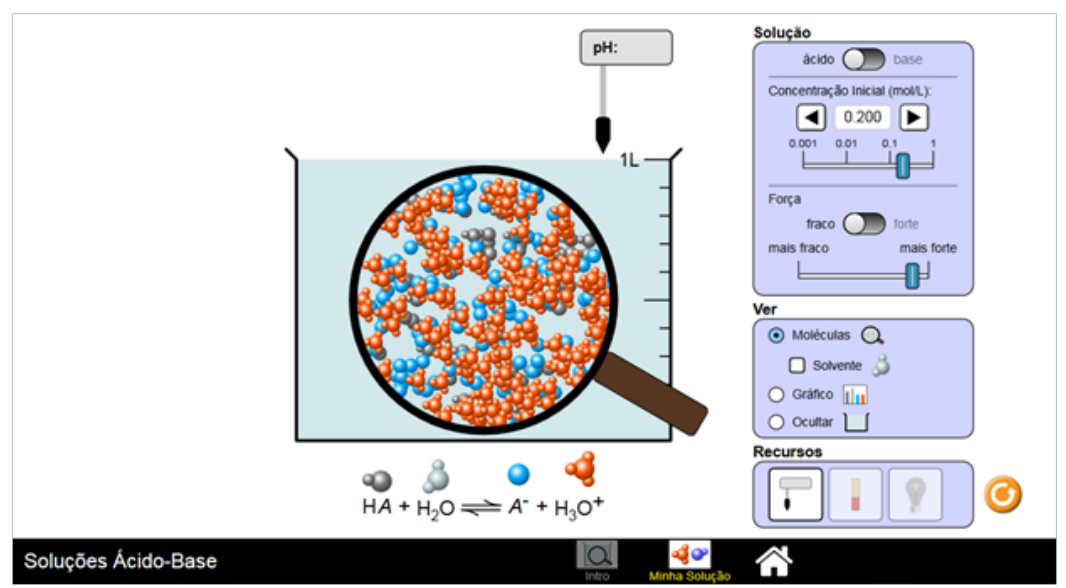

Fonte: Site PhET

P/Ulails Salvador, v. 4, n. 2, p. 47-64, mai./ago. 2019 
O intuito era que os estudantes percebessem que a força está ligada às características do ácido. Logo quando uma solução é mais concentrada a força do ácido não muda apenas mais produtos são formados, pois mais ácido foi adicionado.

Os registros a seguir indicaram que os estudantes entenderam os conceitos científicos, pois a expressão "aumentaram proporcionalmente" nos diz que o ácido não ficou forte, apenas mais íns foram formados porque mais reagente foi adicionado.

R02: "Não. A concentração não mudaria sua força, pois os valores dos ácidos aumentariam proporcionalmente. Um ácido fraco continuaria fraco e um ácido forte continuaria forte."

R01: "Quanto maior a concentração inicial, maior vai ser a concentração das espécies, que é constante."

R01: "O ácido forte reage melhor com a água, pois as partículas se quebram e se juntam com a água."

Os estudantes observaram que espécies são ácidas e básicas em água quando sofrem reação química formando novas espécies e podemos inferir que conseguiram compreender o aspecto particular dessas espécies, como indicado nos excertos a seguir:

R00: "No gráfico é possível notar a ausência de $\mathrm{MOH}$, ou seja todas foram dissolvidas."

R06: "O ácido fraco possui resistência para se dissociar."

R11: "As moléculas ao se chocarem formou uma grande quantidade de íons, tanto na base forte quanto no ácido forte."

\section{Aplicando o conhecimento em diferentes situações}

Em um contexto diferente da simulação, os estudantes deveriam aplicar os conhecimentos adquiridos a fim de explicar a possível reação da fumaça que saía do vulcão contendo ácido com a água do mar. Eles explicaram que como o ácido clorídrico é um ácido forte, ele sofreria ionização liberando íons.

E19: "Os íons $\mathrm{H} 3 \mathrm{O}+$ são gerados a partir do contato das partículas de lava com a água atmosférica."

E21: “(o laze) acontece quando as substâncias da lava evaporam-se e dissolvemse com a água, formando $\mathrm{H} 3 \mathrm{O}+$ (ácido) [...]”

E2: "A nuvem se encontra com a água do mar, e as partículas do $\mathrm{HCl}$ (ácido clorídrico) se separam ficando assim: $\mathrm{H}+$ e $\mathrm{Cl}-$. A partícula $\mathrm{H}+$ se junta a molécula da água (H2O) e forma a molécula $\mathrm{H} 3 \mathrm{O}+$ que caracteriza um ácido." 
Os estudantes conseguiram concluir que o ácido clorídrico reage com a água formando íon hidrônio e íon cloreto devido ao fato de na simulação eles conseguirem visualizar e explorar este modelo para ácidos, em que os ácidos em solução se ionizam formando outras partículas que os caracterizavam como ácidos. Logo, a simulação aliada à abordagem investigativa contribuiu para que os estudantes pudessem compreender a natureza particular da matéria e o comportamento de ácidos e bases em solução aquosa.

Ensinar definições prontas em sala de aula pode ser uma das causas das dificuldades dos estudantes na aprendizagem do modelo submicroscópico do conceito de ácido e base. Para sanar tal questão, as simulações computacionais se tornam aliadas, pois, verificou-se que os estudantes conseguiram, em novo contexto de estudo explicar o fenômeno que estava descrito por extenso na reportagem.

\section{Considerações finais}

A simulação computacional aliada à uma abordagem investigativa proporcionou os estudantes lidarem com um importante conceito da Química, o de ácidos e bases segundo a definição de Arrhenius e a força dessas substâncias. Os grupos trabalharam sobre uma abordagem investigativa que visava engajar os estudantes na construção do próprio conhecimento, executando uma simulação que os ajudava a transitar no nível simbólico e submicroscópico. Construir os conceitos não é algo simples e não era ingenuamente esperado que os estudantes estivessem com eles formalizados a partir de apenas uma sequência de aulas. Mas, esperava-se contribuir com uma visão mais completa em relação às abordadas tradicionalmente.

A sequência aqui proposta pode servir de auxílio para os professores em seu ambiente de trabalho de acordo com a especificidade de seus contextos. Não só as simulações computacionais, mas as TIC's (Tecnologias de Informação e Comunicação) são instrumentos importantes, pois podem contribuir para uma educação que se engaje em formar cidadãos que consigam resolver problemas através da coleta, análise e síntese de variáveis de maneira conectada e crítica.

\section{REFERÊNCIAS}

BRASILEIRO, L. B. SILVA, G. R. In: MATEUS, L. A. (org.). Ensino de Química Mediado pelas TICs. p. 41-66. 1. ed. Belo Horizonte: Editora UFMG, 2015.

DRIVER, R. ASOKO, H. LEACH, J. MORTIMER, E. SCOTT, P. Construindo conhecimento científico na sala de aula. Química Nova na Escola, n. 9, 1999. 
GIORDAN, M. O Papel da Experimentação no Ensino de Ciências. Química Nova na Escola, n. 10, p. 43-49, 1999.

JOHNSTONE, A. H. Macro- and micro-chemistry. School Science Review, v. 64, p. 377-379, 1982.

LEMKE, J. L. Aprendendo a hablar ciências: Linguagem, aprendizajem y valores. Barcelona: Paidos, 1997.

MINAS GERAIS - SECRETARIA DE EDUCAÇÃO DO ESTADO DE (SEE-MG), Conteúdo Básico Comum, 2008.

MORAES, R. GALIAZZI, M. C. Análise Textual Discursiva. Ijuí: Ed. Unijuí, 2007.

OLIVEIRA, A. M. Concepções Alternativas de estudantes do Ensino Médio sobre ácidos e bases: um estudo de caso. 2008. Dissertação de Mestrado - Universidade Federal do Rio Grande do Sul, Porto Alegre, 2008.

PAULA, H. F. As Tecnologias de Informação e Comunicação, Ensino e Aprendizagem de Ciências Naturais. In: MATEUS, L. A. (org.). Ensino de Química Mediado pelas TICs. p. 169195. $1^{\text {a }}$ ed. Belo Horizonte: Editora UFMG, 2015.

RAMOS, M. G. RIBEIRO, M. E. M. GALIAZZI, M. C. Análise Textual Discursiva em processo: investigando a percepção de professores e licenciandos de Química sobre aprendizagem. Campo Abierto, v. 34, n. 2, p. 125-140, 2015.

RIBEIRO, A. A. GRECA, I. M. Simulações computacionais e ferramentas de modelização em educação química: uma revisão de literatura publicada. Química Nova, v. 26, n.4, 542-549, 2003.

Enviado em: 08 de julho de 2019

Apreciado em: 30 de julho de 2019

Inserido em: 01 de agosto de 2019 